Paper 4. Tuu, H. H., Olsen, S. O. \& Linh P. T. T.

The moderator effects of perceived risk, objective knowledge and certainty in the satisfaction-loyalty relationship. Accepted by Journal of Consumer Marketing. 



\title{
The moderator effects of perceived risk, objective knowledge and certainty in the satisfaction-loyalty relationship
}

\author{
Ho Huy Tuu \\ Svein Ottar Olsen \\ Pham Thi Thuy Linh
}

Send correspondence to Ho Huy Tuu, Economics Faculty, University of Nhatrang, N-02

Nguyen Dinh Chieu, Nhatrang, Vietnam, e-mail: tuu_hohuy@yahoo.com.

Svein Ottar Olsen, Troms $\varnothing$ University Business School, University of Troms $\varnothing$, N-9037

Tromsø, Norway, e-mail: svein.o.olsen@uit.no.

Pham Thi Thuy Linh, Vietnam Institute of Fisheries Economics and Planning, N-10,

Nguyen Cong Hoan, Badinh, Hanoi, Vietnam, e-mail: thuylinh_vifep@yahoo.com.

This work was performed within the SRV 2710 - NORAD Project. The authors gratefully acknowledge the Norwegian Government's financing of the work.

Target journal: Journal of Consumer Marketing

Paper type: Research paper.

July 2010 


\title{
The moderator effects of perceived risk, objective knowledge and certainty in the satisfaction-loyalty relationship
}

\begin{abstract}
Purpose - This study discusses and tests the combined role of perceived risk, objective knowledge and certainty as moderators in the satisfaction-loyalty relationship.

Design/methodology/approach - The authors use survey data of 387 Vietnamese
\end{abstract} consumers in a food context. A structural equation modelling (SEM) approach for moderator analysis with latent constructs is used to test the hypotheses.

Findings - Perceived risk is a barrier in the forming of loyalty with a negative moderating effect on the satisfaction-loyalty relationship. However, the satisfaction-loyalty relationship is stronger when objective knowledge and certainty increase.

Research limitations/implications - Our object and setting is limited to one product category in one market. In addition, other moderators (e.g., situation and ambivalence) can be added. The nature of causality is problematic due to the use of survey design.

Practical implications - Customer management based on satisfaction is not sufficient to keep customers' loyalty, especially in the situations of highly perceived risk and uncertainty. Marketing strategies, which reduce consumers' risks, consolidate their confidence and educate them with relevant knowledge, may be effective strategies to increase their loyalty.

Originality/value - The study fills several gaps in the present literature. First, it overcomes some shortcomings of previous studies of moderators in the satisfaction-loyalty relationship by testing the combined role of three important moderators. Second, it tests the moderator effect of objective knowledge and adds an additional explanation to previous studies. While some previous studies suggest a negative moderator effect of subjective knowledge, this paper argues for and confirms a positive moderator effect of objective 
knowledge on this relationship. Finally, it uses SEM for moderator analysis with latent constructs.

Keywords Satisfaction, Loyalty, Perceived risk, Objective knowledge, Certainty.

Paper type Research paper 


\section{Introduction}

There is a "new" stream of research suggesting that the relationship between satisfaction and loyalty is affected by moderators and mediators (Homburg and Giering, 2001; Seiders et al., 2005). The moderation perspective suggests that a moderator(s) interacts with satisfaction to influence the strength or direction of the relationship between satisfaction and loyalty (intentional and actual) (Baron and Kenny, 1986). Currently, most studies of the moderator effects between satisfaction and loyalty use multi-group analyses for testing moderators separately but interpret the results together to describe the combined effects (e.g., Evanschitzky and Wunderlich, 2006; Homburg and Giering, 2001). However, recent research suggests that two or more moderators can perform a combined effect on the satisfaction-loyalty relationship (e.g., Chandrashekaran et al., 2007; Seiders et al., 2005). Therefore, this study discusses and extends the previous literature by performing an empirical test of the combined role of perceived risk, objective knowledge and certainty as moderators in the satisfaction-loyalty relationship using a moderated structural equation model. This is important because there is a wide range of phenomena where these variables appear to influence simultaneously consumers' attitudes/satisfaction and behaviours/loyalty as well as the relationship between these constructs (e.g., Chen and Li, 2007; Klerck and Sweeney, 2007; Laroche et al., 1996; Tuu and Olsen, 2009).

Perceived risk as consumers' subjectively determined expectations of loss is an important construct in explaining and understanding consumer evaluation, choice and buying behaviour (Bauer, 1960; Dowling and Staelin, 1994; Mitchell, 1999). Even though the "objective risk" with the products and services is decreasing, perceived risk and scares seem to be a growing phenomenon in several areas of consumption. For example, in the food area, the consumers' concerns, worry and risk perceptions have increased along with a wide range of product scares such as mad cow disease in Europe or melamine in milk 
from China. The information about the products and consumer knowledge about product risk enhanced by media and consumers' organizations may be the reasons for this phenomenon (Lobb et al., 2006). Such happenings have caused significant reductions in the consumption of the affected products (Angulo and Gil, 2007). Therefore, it is important to develop a deeper understanding of how perceived risk interacts with satisfaction and influences intentional or behavioural loyalty (Grewal et al., 2007). This study also uses a global measure of perceived risk, including physical, performance, psychological and financial aspects.

It has for a long time been suggested that increasing consumers' knowledge is an important strategy to reduce perceived risk because more information or experiences result in a learning process that leads consumers to perceive less risk (Roselius, 1971). Thus, the inclusion of both consumer knowledge and perceived risk may limit biased estimates due to missed variables. Knowledge is often measured either objectively or subjectively (Cordell, 1997). However, most studies measure consumer knowledge subjectively and suggest that subjective knowledge moderates the satisfaction-loyalty relationship negatively (Capraro et al., 2003; Cooil et al., 2007; Evanschitzky and Wunderlich, 2006; Tuu and Olsen, 2009). Thus, it is difficult to decompose knowledge effects from other variables with which this construct is correlated, such as attitude certainty, extremity and accessibility (Fabrigar et al., 2006). To overcome this shortcoming, the present study aims to extend the previous literature by testing the moderator role of objective knowledge in the satisfaction-loyalty relationship.

Similarly to knowledge, certainty or confidence is suggested as being the most important aspect of a deeper understanding of perceived risk (Mitchell, 1999), and Dowling and Staelin (1994, p. 119) discuss uncertainty as one of the most basic attributes of perceived risk. Certainty as a person's degree of conviction or state of feeling sure that his or her evaluation of a product or attribute is correct (Howard and Sheth, 1969) is a 
well-established construct in the consumer attitude-intention literature (Bennett and Harrell, 1975; Laroche et al., 1996). Certainty in evaluating satisfaction is suggested as an important moderator affecting the satisfaction-loyalty relationship (Dick and Basu, 1994; Olsen, 1999 for a discussion), but very little empirical evidence is provided in the area of the satisfaction-intention relationship (Chandrashekaran et al., 2007; Spreng and Page, 2001; Yi and La, 2003). To the best of our knowledge, no study combines both certainty and perceived risk in a satisfaction-loyalty relationship framework.

The purpose of this study is to explore the combined roles of perceived risk, consumer objective knowledge and certainty as moderators in the satisfaction-loyalty relationship. The combined effect here is understood as a sum of the effects of these moderators on the satisfaction-loyalty relationship in addition to their individual moderator effect and traditional direct effects on loyalty (see Seiders et al., 2005). This type of study is especially important for managers who want to gain a deeper understanding of the complicated relationship between satisfaction and loyalty and know more about which types of customers tend to be less loyal even though they may be highly satisfied (Homburg and Giering, 2001). For example, will a satisfied consumer with a high perception of risk continue to be loyal if he or she possesses a high amount of relevant knowledge about a product? According to the research objectives, this study uses structural equation modelling for moderator analysis with latent constructs (Aiken and West, 1991; Ping, 1996) to test a proposed model and research hypotheses.

\section{Theoretical framework}

\section{Consumer satisfaction and loyalty}

Satisfaction has been defined and measured in different ways over the years (Oliver, 1997). One of the latest formal definitions of satisfaction as a composite construct of an overall evaluation has been developed by Oliver (1997), who proposed it to be “the consumer's 
fulfillment response, the degree to which the level of fulfillment is pleasant or unpleasant" (p. 28). This study defines satisfaction as a consumer's accumulative (Johnson et al., 1996) overall evaluation of positive affective responses (Oliver, 1997) of a given product category (Olsen, 2007).

The most widely agreed-upon definition of loyalty is a behavioural response expressed over time (Dick and Basu, 1994). Oliver (1997) defines loyalty as "a deeply held commitment to repurchase a preferred product or service in the future” (p. 392). Combinations of past frequent behaviour and intention to repurchase (e.g., Nijssen et al., 2003; Pritchard et al., 1999) are also used to assess a global and cumulative loyalty measure. Thus, loyalty is in this study defined as a cumulative construct including both the act of consuming (action loyalty) and expected consumption (future repurchasing) in terms of Oliver's $(1997 ; 1999)$ recent loyalty framework.

Researchers assume that the relationship between satisfaction and the different facets of attitudinal, intentional and behavioural loyalty is positive, but varies between products, industries and situations (Szymanski and Henard, 2001). The few empirical studies that test the relationship between satisfaction and perceived or actual buying behaviour or loyalty have suggested a moderate to low relationship compared with studies assessing attitudinal and intentional loyalty (Bloemer and de Ruyter, 1998; Mittal and Kamakura, 2001; Szymanski and Henard, 2001). In addition, most studies testing the moderator effect between satisfaction and loyalty use an attitudinal or intentional assessment of loyalty. This study aims to contribute to the very few studies where loyalty is defined as a cumulative construct and is assessed by behavioural frequency measures of loyalty in combination with intention to buy in the future.

H1: Satisfaction has a positive effect on loyalty. 


\section{Perceived risk}

There is no widely accepted definition of perceived risk within the field of consumer behaviour literature, and it often varies according to the context of study (Conchar et al., 2004). Generally, perceived risk is considered as a multi-aspect construct that includes potential financial (losing or wasting income), performance (does not meet the need), physical (personal illness, injury or health risk), psychological (emotional pressure) or social losses (being seen as unfashionable or having a lower status) associated with a purchase decision (Jacoby and Kaplan, 1972; Yuksel and Yuksel, 2007). Some recent studies apply this multidimensional perspective to marketing in general (McCarthy and Henson, 2005; Yuksel and Yuksel, 2007). They have proved that different dimensions of risk are formed from the same mental schema and have similar effects on consumers' evaluations and behaviours although the magnitudes of their effects are different. For example, in a study of differences in perceived risk between store brands and national brands, Mieres et al. (2006) structure the multidimensional construct of overall risk to include six different dimensions of perceived risk (e.g., functional, financial, social and physical). Similarly, Goodwin (2009) suggests a measurement model of overall perceived risk in which the overall perceived risk is counted as the sum of the products of subjective probability of negative consequences by the judged importance of corresponding negative consequences with six different dimensions of perceived risk as components.

This study keeps to the idea that perceived risk has different dimensions, but includes these dimensions in a general construct and defines perceived risk as consumers' perceptions of the negative consequences associated with consuming a particular product category (Dowling and Staelin, 1994). In the other words, this study approaches perceived risk as an integral construct (Featherman and Pavlou, 2003; Mieres et al., 2006; Stone and Mason, 1995) associated with important consequences related to health, performance, 
financial and social risks (McCarthy and Henson, 2005; Yuksel and Yuksel, 2007). Thus, it is more appropriate to define a global assessment of perceived risk as a moderator (Campbell and Goldstein, 2001; Gurhan-Canli and Batra, 2004) compared with risk as an attribute (antecedents) forming the general evaluation of or satisfaction with a product (e.g., Angulo and Gil, 2007; Tuu and Olsen, 2009).

Gurhan-Canli and Batra (2004) explore the moderator role of perceived risk in the link between product evaluations and choice. Campbell and Goldstein (2001) find that perceived risk moderates the effect of incongruity on evaluations and that preferences for incongruity will not appear when risk is high. When perceived risk exceeds individual tolerance levels, consumers often manage to reduce the negative effect of risk by such methods as obtaining additional information (Mitchell, 1999), switching to substitutes with low levels of risk (Yuksel and Yuksel, 2007) or careful evaluations of alternatives and product trials (Cho and Lee, 2006; Dowling and Staelin, 1994). These actions may lead to a decrease in the predictive power of satisfaction on loyalty because satisfaction can be susceptible, especially with the presence of the increased attractiveness of alternative suppliers that reduces attitudinal shifts and causes deleterious effects on the strength of satisfaction (Oliver, 1999). Moreover, perceived risk often relates to losses and future uncertainty consequences (Dowling and Staelin, 1994) as well as damaging perceived benefits (Saba and Messina, 2002). Thus, it is reasonable to anticipate that when consumers perceive high levels of perceived risk, their expectations and satisfied feelings are formed with less stability. This idea, that highly perceived risk may cause consumers' unstable feelings, is supported by Bauer (1960). Generally, these discussions imply that the predictive strength of satisfaction on loyalty decreases when perceived risk increases.

H2: Perceived risk has a negative moderating effect on the satisfaction-loyalty relationship. 


\section{Consumer knowledge}

Consumer knowledge is suggested to affect how consumers gather and organize information, what products they buy and how they use them (Alba and Hutchison, 1987). Knowledge has traditionally been regarded as a multidimensional construct and mostly categorized as familiarity and expertise (Cordell, 1997). Familiarity is a function of product-related experiences that have been accumulated by the consumer whereas expertise is as the ability to perform product-related tasks (Alba and Hutchison, 1987). Knowledge is often measured either objectively or subjectively (Cordell, 1997). While subjective knowledge refers to a person's perception of the amount of knowledge he or she has about an object and activity, objective knowledge pertains more to the actual amount of knowledge that the person stores in his or her memory (Klerch and Sweeney, 2007). Although subjective and objective knowledge is often correlated (e.g., Cordell, 1997), objective knowledge is suggested to better represent the actual memory content (Brucks, 1985), stored product class information (Park et al., 1994) and as a better measure than subjective knowledge to reflect the predictive strength of attitudes (Fabrigar et al., 2006). Naturally occurring correlations between subjective and objective knowledge poses a problem with separating the effect of each knowledge type if both are included in a model (Raju et al., 1995). In addition, the moderator effect of subjective knowledge on its consequences is difficult to isolate with the ones of other constructs which it relates, such as accessibility or certainty because both subjective knowledge and these related constructs are all consequences of objective knowledge (Smith et al., 2008). Thus, in this study, consumer knowledge as a moderator is defined as objective evaluations about the familiarity and expertise that the person has with a product category (Alba and Hutchison, 1987; Cordell, 1997; Klerch and Sweeney, 2007).

As mentioned in the introduction, subjective knowledge as market expertise is suggested as a moderator in the satisfaction-loyalty relationship in some studies (Cooil et 
al., 2007; Evanschitzky and Wunderlich, 2006; Tuu and Olsen, 2009), in which higher knowledge often leads to a lower predictive power of satisfaction on loyalty. However, consumers often consider how informative their attitude is to the specific behaviour in question and, if the content and dimensions of knowledge on which the attitude is based are directly relevant to the goal of the behaviour, the attitude is a valid guide for the behaviour (Fabrigar et al., 2006). Thus, the moderator role of knowledge in the satisfaction-loyalty relationship may be different depending on the nature, level and content of knowledge as well as how this construct is measured (Cordell, 1997; Fabrigar et $a l .$, 2006). Furthermore, as long as customers are satisfied, the strength of the satisfactionloyalty relationship is expected to be greater if satisfaction and loyalty responses are formed under the central processing enabled by high knowledge (Chiou et al., 2002 for a theoretical discussion). Therefore, this study expects that, to the extent that satisfaction is formed from underlying relevant knowledge, the satisfaction ratings of consumers with higher objective knowledge about a product will be more accessible and more stable than those of consumers with lower knowledge (Fabrigar et al., 2006). This implies that increased objective knowledge is likely to enhance the strength of satisfaction, which is a vital determinant of customer vulnerability because it plays a crucial role in the translation of stated satisfaction into customer loyalty (Chandrashekaran et al., 2007). Thus, general attitude strength theory (Fabrigar et al., 2006) suggests that more knowledge forms stronger attitudes (e.g., satisfaction) and increases the correspondence between attitude and behavioural components.

H3: Objective knowledge moderates positively the satisfaction-loyalty relationship. 


\section{Certainty}

Certainty refers to the amount of confidence a person attaches to an attitude (Olsen, 1999).

Certainty has been described as an evaluative mechanism by which individual consumers assess whether their beliefs about brands and alternatives are accurate or correct (Dick and Basu, 1994). More recently, certainty has been defined as the sense of conviction with which the satisfaction judgment is held (Chandrashekaran et al., 2007). This study defines certainty as the confidence level of consumers in evaluating their satisfaction with regard to consuming a product category.

Olsen (1999) suggests that consumers with low certainty in their evaluations (i.e., attitudes or satisfaction) have a tendency to select one of the neutrality values on a bipolar scale, while high-certainty consumers are more extreme in their evaluations of products. Thus, consumers with high certainty in their evaluations of products often confirm higher attitude-buying behaviour relationships than the low-certainty group (Olsen, 1999). The potential interaction between certainty and satisfaction has been discussed in several previous pieces of research (Dick and Basu, 1994; Oliver, 1997). Certainty is associated with the formation of consumer satisfaction (Spreng and Page, 2001). Consumers with more confidence would believe that not only the favourable outcome (i.e. satisfaction) should be ascribed to their own action, but also that the cause of a prior favourable outcome will endure in the future (Campbell et al., 2004). Thus, satisfaction has a higher impact on loyalty for consumers with higher confidence (Wu and Chang, 2007). The moderating effect of certainty in the satisfaction-loyalty relationship means that customers who hold certain feelings of satisfaction about the product exhibit a stronger satisfactionloyalty relationship than customers with uncertainty feelings (Chandrashekaran et al., 2007). Based on these discussions, the following hypothesis is proposed.

H4: Certainty moderates positively the satisfaction-loyalty relationship.

Based on the suggested hypotheses, the theoretical model is depicted in Figure 1. 


\section{Figure 1 about here}

\section{Methods}

\section{Products and sample}

Food products have been the most used products or objects in studies of perceived risk and consumer knowledge in the area of marketing (Chen and Li, 2007; Klerck and Sweeney, 2007; Tuu and Olsen, 2009) even though it can be a problem that consumers are so little involved with some food products that there is minimal perceived risk (Mitchell, 1999). Consuming food in general is probably more risky in Vietnam than in most Western countries. Marine fish is chosen as the research object in this study for several reasons. First, marine fish is a mainstay of Vietnamese diets, ensuring a high incidence rate of familiarity with the product category. Second, the process from exploration to supplying consumers is quite long and fish is often stored and preserved by chemicals, thus it is difficult for consumers to evaluate the quality of marine fish. Third, because marine fish is also a product with a strong and distinctive smell, many people, especially children, do not actually like to eat it. In addition, the consumption of marine fish in general in Vietnam is mainly from local markets with mostly unbranded products; thus, it is influenced strongly by potential risks (Tuu and Olsen, 2009). As a result, consumers may face health, performance as well as psychological risk. Next, fish seems to be more important for the industry because Vietnam also exports a lot of fish to other countries with a revenue of over 1 billion US dollars in recent years ${ }^{1}$. Finally, focusing on an important product category for the population may reduce the possibility of low involvement with the offering (Dholakia, 2001; Mitchell, 1999).

Data from 387 consumers who are responsible for preparing everyday main meals for their family were conveniently collected at 5 local markets in Hanoi city, Vietnam, by a

\footnotetext{
${ }^{1}$ Statistics from General Statistics Office of Vietnam, 2009.
} 
survey questionnaire administered using "face-to-face" interviewing. The respondents are clearly informed that this study focuses on marine fish, thus only consumers who eat marine fish at least in average once a week are chosen. The typical respondents are female $(64.5 \%)$, married $(74.9 \%)$, educated for up to 15 years $(69.2 \%)$ and their average age is 43 years, ranging from 20 to 79.

\section{Measurement}

The respondents are asked to indicate the level of their satisfaction on a seven-point semantic differential scale with three items in the form: "When I eat marine fish, I feel": (1) Unpleasant/Pleasant, (2) Unsatisfied/Satisfied and (3) Dull/Exciting. These items are frequently used to assess satisfaction as a global evaluation (Olsen, 2007).

A combination of repurchase behaviour and intention to purchase has been used as a cumulative measure of loyalty (Nijssen et al., 2003; Pritchard et al., 1999), and a similar approach was taken here. This study uses five items, one for general frequency, one for recent frequencies and three for behavioural expectance. The general frequency measure of behaviour uses a one-year time frame and a seven-point scale in the form "How many times - on average - during the last year have you eaten marine fish for an everyday meal in your home?": $1=1-2$ times a week, $2=3-4$ times a week, $\ldots$ and $7=$ much more. Recent frequency is assessed with one numeric scale in the form "Could you please estimate how many times you have eaten fish:__times during the last 7 days not including today". The three items are then averaged to form a new indicator measuring recent frequency $($ Cronbach's alpha $=0.79)$. The next three questions, "How many times in the next 7 days do you intend, expect and want to buy and eat marine fish for your everyday main meals: from 1 to 14 or more times?", assess the third measure, framed as a behavioural expectation (alpha $=0.94)$. 
Perceived risk is assessed by asking the respondents to indicate their evaluations on four aspects of perceived risk (performance, financial, health and social) on a seven-point Likert scale, using items adapted from previous studies (Jacoby and Kaplan, 1972; McCarthy and Henson, 2005) (see Appendix). Consumer risk perceptions are widely understood to be an integral factor that influences consumers (Mieres et al., 2006) and the aspects of consumer risk perceptions may act alone or in combination to represent a consumer's overall risk perception (Goodwin, 2009). Therefore, these items of each aspect are averaged to form a new general indicator of overall perceived risk. The same procedure is used by previous studies (e.g., Featherman and Pavlou, 2003; Stone and Mason, 1995).

Objective knowledge about fish in general is measured with nine true/false questions. Five of the statements are true: "To a certain extent, I know that using storing chemicals reduces fish quality"; "Fish is a source of omega-3 fatty acids"; "Pangasius is a fatty fish"; "Saba is a lean fish"; "Some fish contain toxic substances". Four of the statements are false: "Fish is a source of dietary fibre"; "All bacteria found in fish are harmful"; "Natural fish is better for health than farmed fish"; "Almost all fish contains mercury". These questions are adapted from previous studies (Pieniak et al., 2007). We opt not to include a "don't know" answer, which forced respondents to think and make up their mind about the proposed statements. The "right answer" is given one point and a sum of these points generates the numeric measure of objective knowledge.

Certainty has usually been measured by asking people how certain or how confident they are about their satisfaction judgments regarding the evaluated object (Laroche et al., 1996). This study develops a multi-item scale to measure the certainty construct so that each evaluation on each item of the satisfaction scale in the left column corresponds to one item in the right column in the form: "How confident do you feel with your evaluation of these items: (1) Totally not confident/ (7) Totally confident" (Spreng and Page, 2001; Yi and La, 2003). 


\section{Analytical procedure}

First, the study assesses the intended constructs to ensure the internal consistency and the convergent and discriminant validity of the constructs (Anderson and Gerbing, 1988) by performing a confirmatory factor analysis using AMOS. Second, it tests the hypotheses using the two-step estimation approach developed by Ping $(1995 ; 1996)$ for modelling latent variable interactions. This approach overcomes the limitations of other alternatives, such as indicant product analysis (Kenny and Judd, 1984), which can be tedious to use (Ping, 1995), subgroup analysis, which can lead to a reduction of statistical power (Jaccard et al., 1990), or multivariate regression, which does not account for measurement errors (Aiken and West, 1991). Furthermore, Cortina et al. (2001) have shown that this approach generates results totally similar to those estimated by different procedures in SEM for testing moderators (see Cortina et al., 2001 for a review), but it is more straightforward conceptually and operationally.

\section{Analysis and results}

\section{Reliability and validity}

The results, summarized in Table 1, indicate that the measurement model fits very well with the data $\left(\chi^{2}=116.9, d f=68, p<0.001 ; \mathrm{RMSEA}=0.04 ; \mathrm{GFI}=0.96 ; \mathrm{CFI}=0.99\right)$ (Browne and Cudeck, 1992). All the composite reliability exceeds the minimum value of 0.60 and, except for the scale of perceived risk (0.45), the variances extracted surpass the recommended threshold of 0.50 (Anderson and Gerbing, 1988). The individual item loadings on the constructs are all highly significant $(p<0.001: t$-value $>10)$ with values ranging from 0.54 to 0.96 , which show that the convergent validity and reliability of the constructs are acceptable.

Tables 1 and 2 are about here 
As shown in Table 2, all the correlations are less than 0.60, and the squared correlation between each of the constructs (the highest value at 0.39 ) is less than the average variance extracted from each pair of constructs (the lowest value at 0.45 ), which constitutes discriminant validity (Fornell and Larcker, 1981).

\section{Testing hypotheses}

This study uses Ping's (1996) two-step estimation approach developed for modelling latent variable interactions. First, all the origins of scales of the constructs are changed by meancentering to reduce the correlations between the involved constructs and their interactions (Aiken and West, 1991). Then, the average scores of the indicators of latent variables involved in the interactions are multiplied to form interactions. Note that objective knowledge has only one item, thus the error variances of objective knowledge are fixed by $15 \%$ of its variance (Joreskog and Sorbom, 1982). Next, the factor loadings and the error variances of these interacting measures are fixed by particular values based on the formulas provided by Ping (1996) using parameter estimates from the measurement model (Table 1) as inputs (see Ping, 1995; 1996 for more details).

The following system of structural equations expresses the structure of the full model in Figure 1.

$\mathrm{L}=\beta_{1} \mathrm{~S}+\beta_{2} \mathrm{~S} \times \mathrm{R}+\beta_{3} \mathrm{~S} \times \mathrm{OK}+\beta_{4} \mathrm{~S} \times \mathrm{C}+\beta_{5} \mathrm{R}+\beta_{6} O \mathrm{~K}+\beta_{7} \mathrm{C}+\varepsilon$

L: loyalty; S: satisfaction; R: perceived risk; OK: objective knowledge; C: certainty.

First, the significance of the coefficient of $\beta_{l}(\mathrm{H} 1)$ indicates a direct effect of satisfaction on loyalty. Second, the study assesses the moderating effects of perceived risk, objective knowledge and certainty on the satisfaction-loyalty relationship (H2, H3, H4) by considering the significance of the coefficients of $\beta_{2}, \beta_{3}$ and $\beta_{4}$, respectively (Ping, 1996).

A hierarchical moderated regression analysis using structural equation modelling is used to estimate the effects of the variables and their interactions on loyalty (Aiken and 
West, 1991; Baron and Kenny, 1986). The independent variables and interactions were entered in three blocks, thus three nested models were generated. The first model (Basic Model) estimates the effect of satisfaction on loyalty. The second model (Moderation Model) is added with three moderator effects as in Figure 1. The last model (Extended Model) with direct effects is used to test moderator effects after controlling for direct effects of perceived risk, knowledge and certainty on loyalty. The results indicate the acceptable fits of all the estimated models $(\mathrm{GFI}=0.94-0.99 ; \mathrm{CFI}=0.98-1.00 ; \mathrm{RMSEA}=$ 0.03-0.06) (Browne and Cudeck, 1992). Table 3 presents the standardized beta weights for the predictor variables, the total $\mathrm{R}^{2}$ at each step, and the $\Delta \mathrm{R}^{2}$ for steps $2-3$. Because the estimating results are consistent with each other for the three models, the following conclusions are based on the third model (i.e., Extended Model).

\section{Table 3 is about here}

The main effect of satisfaction. Hypothesis 1 suggested that satisfaction had a positive effect on loyalty. This is a test of the main effect of satisfaction on customer loyalty. The results support this hypothesis by indicating a significant positive effect of satisfaction on loyalty $(\beta=0.45, \mathrm{t}=7.3, \mathrm{p}<0.001)$. This result is necessary for testing further moderating effects on this relationship. If loyalty is regressed only to satisfaction, the magnitude of the association between satisfaction and loyalty is $0.63(\mathrm{t}=12.6)$, which explains the variance of loyalty by $39.6 \%$ (in the Basic Model).

Moderating effects. With the main effect of satisfaction supported, we now turn our attention to the moderating effects that perceived risk, objective knowledge and certainty have on the satisfaction-loyalty relationship. Hypothesis 2 proposed that the positive effect of satisfaction on loyalty would be weaker when perceived risk increases. As expected, this hypothesis is supported by a significantly negative effect of the interaction between perceived risk and satisfaction on loyalty $(\beta=-0.17, \mathrm{t}=-2.5, \mathrm{p}<0.05)$. In contrast to 
Hypothesis 2, Hypotheses 3 and 4 suggested that the positive effect of satisfaction on loyalty would be stronger when objective knowledge and certainty increase. This calls for positive interaction coefficients between satisfaction and objective knowledge, and between satisfaction and certainty. The results support Hypotheses 3 and 4 by showing that the positive effect of satisfaction on loyalty is bolstered for consumers with higher levels of objective knowledge $(\beta=0.14, \mathrm{t}=2.3, \mathrm{p}<0.05)$ and certainty $(\beta=0.19, \mathrm{t}=3.0, \mathrm{p}<0.01)$. Finally, the addition of the three hypothesized interaction terms increases considerably the explained variance of loyalty $\left(R^{2}=44.1 \%\right.$, effect size $\left.[\mathrm{ES}]=0.12\right)$ (in the Moderation Model).

Baseline direct effects. Although we did not hypothesize the direct effects coming along with moderating effects (Seiders et al., 2005) as seen in equation (1), the results offer some inferences worth noting. Except for a nonsignificant effect of objective knowledge ( $\beta$ $=0.07, \mathrm{t}=1.4, \mathrm{p}>0.05)$, both perceived risk and certainty have significant effects on loyalty. Specifically, while certainty has a positive influence on loyalty $(\beta=0.14, t=2.8, p$ $<0.05)$, perceived risk has a negative effect on loyalty $(\beta=-0.32, \mathrm{t}=-5.0, \mathrm{p}<0.001)$. Generally, these findings are consistent with previous studies reporting a significant negative effect of perceived risk on intentional loyalty, willingness to pay, positive word of mouth and behavioural loyalty (Angulo and Gil, 2007; Grewal et al., 2007; Yuksel and Yuksel, 2007) as well as a positive effect of certainty on consumption behaviours (Yi and La, 2003). The inclusion of the direct effects generates an additional explained variance of loyalty of $5.6 \%$ to $49.7 \%(\mathrm{ES}=0.13$, in the Extended Model). 


\section{Discussion}

This study has explored the moderator effects of perceived risk, objective knowledge and certainty on the satisfaction-loyalty relationship in a food context. The proposed hypotheses are tested by a moderated regression analysis in structural equation modelling for latent variables (Aiken and West, 1991; Ping, 1995; 1996) using survey data from Vietnam. The results indicate the reliability and validity of the constructs in the model and the findings support the proposed hypotheses. Therefore, this study generates several contributions both theoretically and practically, particularly because it uses a combination of three moderators while others use single moderator (e.g., certainty) (Chandrashekaran et al., 2007) and multi-group approaches (e.g., Evanschitzky and Wunderlich, 2006).

\section{Theoretical implications}

The present results confirm general marketing studies' positive relationship between satisfaction and loyalty (Szymanski and Henard, 2001). However, as in several previous studies (Bloemer and de Ruyter, 1998; Mittal and Kamakura, 2001; Szymanski and Henard, 2001), the association between satisfaction and loyalty is moderate, and explains about $35.9 \%$ of the variance of loyalty. Therefore, it is necessary to include other variables besides satisfaction in order to understand the barrier and motives to explain variation in loyalty (e.g., Cooil et al., 2007; Olsen, 2007; Seiders et al., 2005). Especially, we extend previous studies (Chandrashekaran et al., 2007; Chiou et al., 2002; Cooil et al., 2007; Evanschitzky and Wunderlich, 2006; Tuu and Olsen, 2009) by testing the combined moderator effects of perceived risk, objective knowledge and certainty on the satisfactionloyalty relationship. The different and combined roles of perceived risk, satisfaction strength (e.g., certainty) and consumer objective knowledge suggested besides satisfaction increase the explained variance of loyalty to $49.7 \%$. 
This study uses a global scale to assess perceived risk, including health, performance, psychological and financial aspects. Perceived risk moderates negatively the relationship between satisfaction and loyalty, or a higher perceived risk leads to a lower predictive power of consumer satisfaction on loyalty. This empirical evidence supports the moderator role of perceived risk in the satisfaction-loyalty relationship as well as extending previous studies to confirm the moderator role of perceived risk in the evaluation/preferencechoice/behaviour relationship (Campbell and Goldstein, 2001; Gurhan-Canli and Batra, 2004). The consideration of the moderator effect of perceived risk in the relationship provides a deeper insight into the mechanism forming loyalty from satisfaction, in which perceived risk acts as a big barrier. This indicates that satisfaction may fail to predict loyalty under highly risky situations, or, in other words, satisfied consumers with high levels of perceived risk may be disloyal consumers. Finally, this study also shows the importance of perceived risk as an integral construct including multidimensions when considering consumer satisfaction and loyalty (McCarthy and Henson, 2005; Yuksel and Yuksel, 2007).

Objective knowledge is found to moderate the satisfaction-loyalty relationship positively. This means that the "true" knowledge based on which consumers form their evaluations and make decisions to continue the consumption of products plays an important role in narrowing the gap between satisfaction and loyalty. Specifically, for lowobjective knowledge consumers, the magnitude of the relationships between satisfaction and loyalty is weaker than for high-objective knowledge consumers. Our results are supported by Chiou et al. (2002) in a service context and in general attitude strength theory (e.g., Fabrigar et al., 2006). However, our findings oppose those of previous studies in marketing, which often focus on consumers' subjective knowledge as market expertise and find a negative moderating effect on the satisfaction-loyalty relationship (Capraro et al., 2003; Cooil et al., 2007; Evanschitzky and Wunderlich, 2006; Tuu and Olsen, 2009). 
Importantly, by using objective knowledge rather than subjective knowledge, this study extends previous studies and confirms that objective knowledge also moderates this relationship positively. Thus, our finding is important and contributes to making clearer the moderator role of consumer knowledge in the movement from consumer satisfaction to loyalty.

This study is among very few studies testing the role of certainty in the satisfactionloyalty relationship (Chandrashekaran et al., 2007) and provides empirical evidence to support previous propositions (Dick and Basu, 1994) that certainty should be a moderator in the satisfaction-loyalty relationship. The result is consistent with Chandrashekaran et al.'s (2007) findings of a positive moderating effect of certainty in the satisfaction-loyalty relationship to confirm that satisfaction strength or certainty plays an important role in the translation of satisfaction into loyalty. However, our study is different from theirs in the aspects of measures and estimate methods. Chandrashekaran et al. (2007) focus on the simultaneous manifestation of uncertainty in the variation surrounding the central tendency of stated judgments. They also suggest that the mean of this distribution is an index of the level of satisfaction, while the variance of the distribution is related to the strength (i.e., conviction or certainty) with which this satisfaction is held. In their approach, both satisfaction and its strength are combined in the same evaluation and a regression analysis is used to separate these two measures. Thus, the satisfaction strength referred to by Chandrashekaran et al. (2007) seems to be a composite construct. It may include not only certainty but also several other aspects of stated judgements, such as stability, ambivalence or extremity, which are geometrically manifested as the same as uncertainty (see Olsen, 1999 for more details). By measuring certainty as an independent construct from satisfaction judgements, this study provides clearer empirical evidence supporting the moderator role of certainty or confidence in the satisfaction-loyalty relationship. 


\section{Conclusion, practical implications and limitations}

As a summary, this study confirms the combined moderator role of perceived risk, objective knowledge and certainty in the satisfaction-loyalty relationship. The findings indicate that the predictive power of satisfaction on loyalty decreases considerably when perceived risk increases, but is enhanced by the higher levels of objective knowledge and certainty. Our findings, therefore, have several managerial implications.

First, customer management based on satisfaction has been confirmed as a vital strategy for companies, but it is not sufficient to keep customers' loyalty (Homburg and Giering, 2001), especially with the presence of high perceived risk. Thus, to enhance consumer loyalty, management attention should focus on risk-reducing strategies for customers in which quality control and management and giving consumers a quality guarantee are two possible strategies (Angulo and Gil, 2007; Tuu and Olsen, 2009). In addition, communication and promotion strategies for safety products should be carried out and attention directed not only to buyers but also to all the members of their family to improve their trust in the products. These strategies are expected not only to consolidate consumer confidence but also to create support from other family members, which helps to reduce the levels of perceptions of social and psychological risks. These findings also indicate that high perceived risk customers are subject to defection, thus enterprises should use loyalty programs to retain them. More importantly, marketing strategies which can compensate for consumers' potential losses in risky situations to confirm with consumers that the actual losses are low may be the most effective ways.

Second, as indicated, consumers with lower objective knowledge about the products often show less loyalty than consumers with higher objective knowledge do. Thus, educating consumers with relevant knowledge may be an appropriate strategy (Chen and Li, 2007; Worsley, 2002). Not only does it help to consolidate consumer loyalty, but it also helps to reduce the negative effect of the perception of risk (Chen and Li, 2007). More 
importantly, because it takes a long time for such knowledge to become practical (Worsley, 2002), enterprises and industries should consider education for their consumers as a long-term strategy rather than only as short-term tactics. In addition, it is important to observe and record consumers' actual knowledge about the product rather than what they perceive about the product.

Third, the inclusion of certainty besides satisfaction in a study of consumer loyalty also has important implications practically. It is a common problem that customers often report their satisfaction with an upward bias, which generates high scores of satisfaction toward products they have experienced (Peterson and Wilson, 1992). This often gives a mistaken impression to marketers about the success of their customer management policy, but actually the ratio of customers' retention is often low to moderate (Szymanski and Henard, 2001). Consistent with previous studies that call for an insight to explain and understand the complex mechanism of consumer satisfaction (Chandrashekaran et al., 2007; Olsen, 2007; Seiders et al., 2005), this study suggests that managers and marketers should not only understand the levels of their customer satisfaction, but also understand its strength. More specifically, the certainty of consumers' feelings needs to be observed and recorded as an important moderator affecting the translation from customers' satisfaction to loyalty.

Finally, this study tests simultaneously three moderators of perceived risk, objective knowledge and certainty in one structural equation model to generate a combined moderator effect. Thus, it helps to overcome several shortcomings of previous studies using subgroup analysis (e.g., Evanschitzky and Wunderlich, 2006), which tests moderators separately and can not account for the contribution of moderators to the explained variance of loyalty (Baron and Kenny, 1986), or using multivariate regression analysis (e.g., Seiders et al., 2005), which ignores measurement errors (Aiken and West, 1991; Ping, 1996). More importantly, the constructs of perceived risk, consumer knowledge and certainty both theoretically and practically have been proved to influence 
simultaneously consumers' evaluations and behaviours (Dowling and Staelin, 1994;

Mitchell, 1999; Roselius, 1971). Therefore, a combination of all these moderators in the satisfaction-loyalty relationship as a common logical framework helps to create a more comprehensive picture of the research phenomenon.

Despite the above contributions, this study has several limitations. The present research is based on a convenience sample in Vietnam with marine fish. Future research should expand to a more representative sample of a population and to other products or services, as well as testing them in other countries or markets. The study has not, because of its unrepresentative sample, considered the different moderators of the satisfaction-loyalty relationship such as customer characteristics (Cooil et al., 2007; Homburg and Giering, 2001; Mittal and Kamakura, 2001) or situational characteristics (Evanschitzky and Wunderlich, 2006; Seiders et al., 2005). Thus, future studies should extend the model to gain a more comprehensive picture of the development of loyalty. It is possible that perceived risk, consumer knowledge and certainty may interact with each other, affecting the satisfaction-loyalty relationship; thus, future studies would benefit from providing both the theoretical mechanism and empirical evidence for that issue in controlled experiments. For example, Raju et al. (1995) suggest that knowledge types could be manipulated orthogonally to assess their independent effects. Such manipulations may allow a more precise study of the two-way and three-way interaction between other moderator variables as well. As mentioned above, the construct of satisfaction strength (Chandrashekaran et al., 2007) may have several aspects. Future studies should extend to include different aspects, such as accessibility, ambivalence or extremity (Olsen, 1999), besides certainty to cover more fully the content of the construct. Finally, the results presented here are based on selfreported measures of satisfaction and repurchase loyalty; hence, erroneous inferences can be produced if common method variance inflates the estimates of the association between them. Thus, objective repurchase loyalty as a dependent measure may give better results 
(Seiders et al., 2005). As with all studies using correlation methods, the nature of the relationships is problematic, thus experimental designs should be used in order to address issues of causality in future studies.

\section{References}

Aiken, L.S. and West, S.G. (1991), Multiple Regression: Testing and Interpreting Interactions, Sage, Thousand Oaks, CA.

Alba, J.W. and Hutchison, J.W. (1987), "Dimensions of consumer expertise”, Journal of Consumer Research, Vol. 13, pp. 411-454.

Anderson, J.C. and Gerbing, D.W. (1988), "Structural equation modelling in practice: a review and recommended two step approach”, Psychological Bulletin, Vol. 103 No. 3, pp. $411-423$.

Angulo, A.M. and Gil, J.M. (2007), "Risk perception and consumer willingness to pay for certified beef in Spain", Food Quality and Preference, Vol. 18, pp. 1106-1117.

Baron, R.M. and Kenny, D.A. (1986), "The moderator-mediator variable distinction in social psychological research: strategic and statistical consideration", Journal of Personality and Social Psychology, Vol. 51, pp. 1173-1182.

Bauer, R.A. (1960), “Consumer behavior as risk taking”, in Hancock, R.L. (Ed.), Dynamic Marketing for a Changing World, American Marketing Association, Chicago, IL.

Bennett, P.D. and Harrell, G.D. (1975), “An evaluation of the expectance/value model of attitude measurement for physical prescribing behavior", Marketing Research, Vol. 11, pp. 269-278.

Bloemer, J.M. and de Ruyter, K. (1998), “On the relationship between store, store satisfaction and store loyalty", European Journal of Marketing, Vol. 32, pp. 499513.

Browne, M.W. and Cudeck, R. (1992), “Alternative ways of assessing model fit”, 
Sociological Methods and Research, Vol. 21 No. 2, pp. 230-258.

Brucks, M. (1985), "The effects of product class knowledge on information search behavior", Journal of Consumer Research, Vol. 12, pp. 1-16.

Campbell, M.C. and Goldstein, R.C. (2001), "The moderating effect of perceived risk on consumers' evaluations of product incongruity: preference for the norm", Journal of Consumer Research, Vol. 28 No. 3, pp. 439-449.

Campbell, W. K., Goodie, A. S., and Foster, J. D. (2004), “Narcissism, confidence, and risk attitude", Journal of Behavioral Decision Making, Vol. 17 No. 4, pp. 297-311.

Capraro, A.J., Broniarczyk, S. and Srivastava, R.K. (2003), "Factors influencing the likelihood of customer defection: the role of consumer knowledge", Journal of the Academy of Marketing Science, Vol. 31 No. 2, pp. 164-175.

Chandrashekaran, M., Rotte, K. and Grewal, R. (2007), "Satisfaction strength and customer loyalty", Journal of Marketing Research, Vol. 44, pp. 153-163.

Chen, M.F. and Li, H.L. (2007), “The consumer's attitude toward genetically modified foods in Taiwan", Food Quality and Preference, Vol. 18, pp. 662-674.

Chiou, J.S., Droge, C. and Hanvanich, S. (2002), "Does customer knowledge affect how loyalty is formed?", Journal of Service Research, Vol. 5 No. 2, pp. 113-124.

Cho, L. and Lee, J. (2006), “An integrated model of risk and risk-reducing strategies”, Journal of Business Research, Vol. 59, pp. 112-120.

Conchar, M.P., Zinkhan, G.M. and Olavariette, S. (2004), “An integrated framework for the conceptualization of consumers' perceived-risk processing", Journal of Academy of Marketing Science, Vol. 32, pp. 418-436.

Cooil, B., Keiningham, T.L., Aksoy, L. and Hsu, M. (2007), “A longitudinal analysis of customer satisfaction and share of wallet: investigating the moderating effect of customer characteristics", Journal of Marketing, Vol. 71, pp. 67-83. 
Cordell, V.V. (1997), “Consumer knowledge measures as predictors in product evaluation”, Psychology and Marketing, Vol. 14 No. 3, pp. 241-260.

Cortina, J.M., Chen, G. and Dunlap, W.P. (2001), “Testing interaction effects in LISREL: Examination and illustration of available procedures", Organizational Research Methods, Vol. 4 No. 4, 324-360.

Dholakia, U.M. (2001), “A motivational process model of product involvement and consumer risk perception”, European Journal of Marketing, Vol. 35 No. 11/12, pp. $1340-1360$.

Dick, A.S. and Basu, K. (1994), "Customer loyalty: toward an integrated conceptual framework", Journal of the Academy of Marketing Science, Vol. 22 No. 2, pp. 99113.

Dowling, G.R. and Staelin, R. (1994), “A model of perceived risk and intended riskhandling activities", Journal of Consumer Research, Vol. 21, pp. 119-134.

Evanschitzky, H. and Wunderlich, M. (2006), “An examination of moderator effects in the four-stage loyalty model", Journal of Service Research, Vol. 8, pp. 330-345.

Fabrigar, L.R., Petty, R.E., Smith, S.M. and Crites, S.L. (2006), "Understanding knowledge effects on attitude-behavior consistency: the role of relevance, complexity, and amount of knowledge", Journal of Personality and Social Psychology, Vol. 90, pp. 556-577.

Featherman, M.S. and Pavlou, P.A. (2003), "Predicting e-services adoption: a perceived risk facets perspective”, International Journal of Human-Computer Studies, Vol. 59, pp. 451-474.

Fornell, C. and Larcker, D.F. (1981), "Evaluating structural equation models with unobservable variables and measurement error", Journal of Marketing Research, Vol. 18, pp. 39-50. 
Goodwin, S.A. (2009), “The concept and measurement of perceived risk: A marketing application in the context of the new product development process", in the Proceedings of ASBBS Annual Conference, Las Vegas, February, 2009, Vol. 16 No. 1 , pp. 142-150.

Grewal, D., Gopalkrisnan, R.I., Gotlieb, J. and Levy, M. (2007), 'Developing a deeper understanding of post-purchase perceived risk and behavioural intentions in a servicesetting", Journal of the Academy of Marketing Science, Vol. 35, pp. 250-258.

Gurhan-Canli, Z. and Batra, R. (2004), "When corporate image affects product evaluations: the moderating role of perceived risk", Journal of Marketing Research, Vol. 41, pp. 197-205.

Homburg, C. and Giering, A. (2001), "Personal characteristics as moderators of the relationship between customer satisfaction and loyalty - an empirical analysis", Psychology and Marketing, Vol. 18 No. 1, pp. 43-66.

Howard, J.A. and Sheth, J.N. (1969). The Theory of Buyer Behavior. New York: John Wiley and Sons, Pnc.

Jaccard, J., Turrisi, R. and Wan, C.K. (1990). Interaction Effects in Multiple Regression. Newbury Park, CA: Sage.

Jacoby, J. and Kaplan, L.B. (1972), “The components of perceived risk”, in Venkatesan, M. (Ed.), Proceedings of the third annual conference of the Association for Consumer Research, Association for Consumer Research, Iowa City, IA, pp. 382393.

Johnson, M.D., Nader, G. and Fornell, C. (1996), “Expectations, perceived performance, and customer satisfaction for a complex service: the case of bank loans", Journal of Economic Psychology, Vol. 17, pp. 163-182.

Joreskog, G.K. and Sorbom, D. (1982), "Recent developments in structural equation modelling”, Journal of Marketing Research, Vol. 19, pp. 404-416. 
Klerch, D. and Sweeney, J. (2007), “The effects of knowledge types on consumerperceived risk and adoption of genetically modified foods", Psychology and Marketing, Vol. 24 No. 2, pp. 171-193.

Laroche, M., Kim, C. and Zhou, L. (1996), "Brand familiarity and confidence as determinants of purchase intention: an empirical test in a multiple brand context", Journal of Business Research, Vol. 37, pp. 115-120.

Lobb, A.E., Mazzocchi, M. and Traill, W.B. (2006), "Modelling risk perception and trust in food safety information within the theory of planned behaviour", Food Quality and Preference, Vol. 18, pp. 384-395.

Malhotra, N.K. and Birks, D.F. (2003). Marketing research: An applied approach. Prentice Hall, Harrow, England.

McCarthy, M. and Henson, S. (2005). "Perceived risk and risk reduction strategies in the choice of beef by Irish consumers", Food Quality and Preference, Vol. 16, pp. $435-445$.

Mieres, C.G., Martin, A.M.D. and Gutierrez, J.A.T. (2006), “Antecedents of the difference in perceived risk between store, brands and national brands", European Journal of Marketing, Vol. 40 No. 1/2, pp. 61-82.

Mitchell, V.W. (1999). "Consumer perceived risk: Conceptualisations and models", European Journal of Marketing, Vol. 33 No. 1/2, 163-195.

Mittal, V. and Kamakura, W.A. (2001), "Satisfaction, repurchase intent, and repurchase behavior: investigating the moderating effect of customer characteristics", Journal of Marketing, Vol. 68, pp. 131-142.

Nijssen, E., Singh, J., Sirdeshmukh, D. and Holzmüeller, H. (2003), “Investing industry context effects in consumer-firm relationships: preliminary results from a dispositional approach", Journal of the Academy of Marketing Science, Vol. 31 No. 1, pp. 46-60. 
Oliver, R.L. (1997), Satisfaction: A Behavioral Perspective on the Consumer, Irwin/McGrawHill, New York.

Oliver, R.L. (1999), "Whence consumer loyalty”, Journal of Marketing, Vol. 63, pp. 33-44.

Olsen, S.O. (1999), "Strength and conflicting valence in the measurement of food attitudes and preferences", Food Quality and Preference, Vol. 10, pp. 483-494.

Olsen, S.O. (2007), "Loyalty: the role of involvement and satisfaction”, Psychology and Marketing, Vol. 24 No. 4, pp. 1-28.

Park, C.W., Mothersbaugh, D.L. and Feick, L. (1994), "Consumer knowledge assessment”, Journal of Consumer Research, Vol. 21, pp. 71-82.

Peterson, R.A. and Wilson,W.R. (1992), "Measuring customer satisfaction: fact and artifact”, Journal of the Academy of Marketing Science, Vol. 20, pp. 61-71.

Pieniak, Z., Verbeke, W., Vermeir, I., Brunso, K. and Olsen, S.O. (2007), “Consumer interest in fish information and labeling: exploratory insight”, Journal of International Food and Agribusiness Marketing, Vol. 19 No. 2/3, pp. 117-141.

Ping, R.A. Jr. (1995), “A parsimonious estimating technique for interaction and quadratic latent variables", Journal of Marketing Research, Vol. 32, pp. 336-347.

Ping, R.A. Jr. (1996), “Latent Variable Interaction and Quadratic Effect Estimation: A Two-Step Technique Using Structural Equation Analysis”, Psychological Bulletin, Vol. 119 No. 1, pp. 166-175.

Pritchard, M.P., Havitz, M.E. and Howard, D.R. (1999), “Analyzing the commitment-loyalty link in service contexts", Journal of the Academy of Marketing Science, Vol. 27 No. 3, pp. 333-348.

Raju, P.S., Lonial, S.C. and Mangold, W.G. (1995), "Differential effects of subjective knowledge, objective knowledge, and usage experience on decision making: An exploratory investigation”, Journal of Consumer Psychology, Vol. 4 No. 2, pp. 153-180. 
Roselius, T. (1971), “Consumer rankings of risk reduction methods”, Journal of Marketing, Vol. 35, pp. 56-61.

Saba, A. and Messina, F. (2002), “Attitudes towards organic foods and risk/benefit perception associated with pesticides", Food Quality and Preference, Vol. 14, pp. 637-645.

Seiders, K., Voss, G.B., Grewal, D. and Godfrey, A. (2005), "Do satisfied customers buy more? Examining moderating influences in a retailing context", Journal of Marketing, Vol. 69, pp. 26-43.

Smith, S.M., Fabbrigar, L.R., MacDougall, B.L. and Wiesenthal, N.L. (2008), “The role of amount, cognitive elaboration, and structural consistency of attitude-relevant knowledge in the formation of attitude certainty", European Journal of Social Psychology, Vol. 38, pp. 280-295.

Spreng, R.A. and Page, J.T. Jr. (2001), “The impact of confidence in expectations on consumer satisfaction", Psychology and Marketing, Vol. 18, pp. 1187-1204.

Stone, R.N. and Mason, J.B. (1995), “Attitude and risk: Exploring the relationship”, Psychology and Marketing, Vol. 12 No. 2, pp. 135-154.

Szymanski, D.M. and Henard, D.H. (2001), "Customer satisfaction: a meta-analysis of the empirical evidence", Journal of the Academy of Marketing Science, Vol. 29 No. 1, pp. 16-35.

Tuu, H.H. and Olsen, S.O. (2009), "Food risk and knowledge in the satisfaction-loyalty relationship", Asia Pacific Journal of Marketing and Logistics, Vol. 21 No. 4, pp. 521-536.

Worsley, A. (2002), "Nutrition knowledge and food consumption: can nutrition knowledge change food behaviour?", Asia Pacific Journal of Clinical Nutrition, Vol. 11, pp. 579-585. 
Wu, W.Y. and Chan, M.L. (2007), "The role of risk attitude on online shopping: experience, customer satisfaction and repurchase intention", Social Behavior and Personality, Vol. 35 No. 4, pp. 453-468.

Yi, Y. and La, S. (2003), "The moderating role of confidence in expectations and the asymmetric influence of disconfirmation on customer satisfaction", The Service Industry Journal, Vol. 23 No. 5, pp. 20-47.

Yuksel, A. and Yuksel, F. (2007), “Shopping risk perception: effects on tourists' emotion, satisfaction and expressed loyalty intentions", Tourism Management, Vol. 28, pp. $303-313$. 


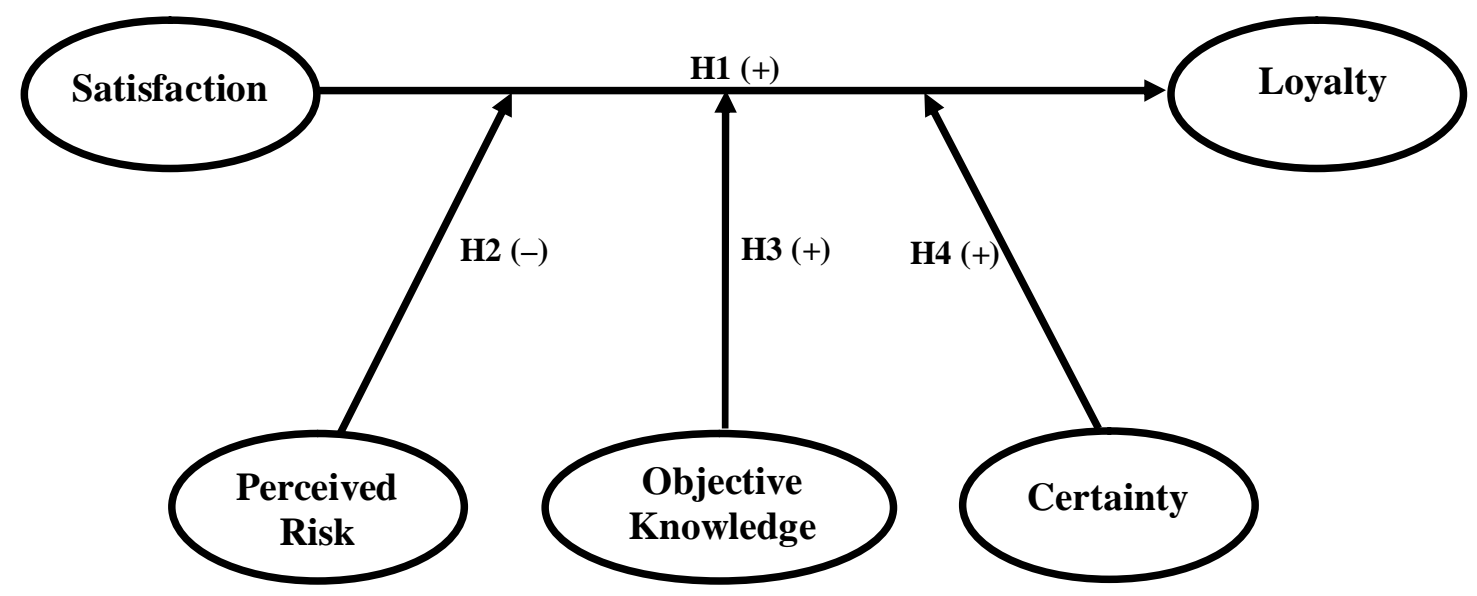

Figure 1: The theoretical model 
Table 1.

Constructs and indicators

\begin{tabular}{|c|c|c|c|c|}
\hline Constructs and indicators & $\begin{array}{l}\text { Factor } \\
\text { loadings }\end{array}$ & $\mathrm{t}$-values & $\begin{array}{l}\text { Composite } \\
\text { reliability }\end{array}$ & $\begin{array}{l}\text { Extracted } \\
\text { variance }\end{array}$ \\
\hline Satisfaction & & & 0.96 & 0.90 \\
\hline Unpleasant/Pleasant & 0.96 & 25.2 & & \\
\hline Unsatisfied/Satisfied & 0.96 & 25.3 & & \\
\hline Dull/Exciting & 0.93 & 24.1 & & \\
\hline Loyalty & & & 0.86 & 0.67 \\
\hline Past frequency & 0.89 & 20.1 & & \\
\hline Recent frequency & 0.83 & 18.8 & & \\
\hline Behavioral expectation & 0.72 & 15.4 & & \\
\hline Certainty & & & 0.95 & 0.86 \\
\hline Certainty - Unpleasant/Pleasant & 0.92 & 23.6 & & \\
\hline Certainty - Unsatisfied/Satisfied & 0.93 & 24.1 & & \\
\hline Certainty - Not liking/Liking & 0.93 & 24.0 & & \\
\hline Perceived risk & & & 0.76 & 0.45 \\
\hline Health & 0.72 & 14.4 & & \\
\hline Performance & 0.54 & 10.3 & & \\
\hline Social & 0.81 & 16.6 & & \\
\hline Financial & 0.56 & 10.7 & & \\
\hline \multicolumn{5}{|l|}{ Objective knowledge } \\
\hline Objective knowledge score & 0.84 & 19.8 & - & - \\
\hline
\end{tabular}

Note.

Fit statistics: $\chi^{2}(68)=116.9, p<0.001 ; \mathrm{RMSEA}=0.04 ; \mathrm{GFI}=0.96 ; \mathrm{CFI}=0.99$

All factor loadings are significant at $p<0.001$. 
Table 2.

Construct means, standard deviations and correlations

\begin{tabular}{lccccccc}
\hline \multicolumn{1}{c}{ Constructs } & M & S.D. & 1 & 2 & 3 & 4 & 5 \\
\hline 1. Satisfaction & 4.14 & 1.73 & - & & & & \\
2. Loyalty & 2.87 & 1.38 & 0.63 & - & & & \\
3. Risk & 4.10 & 1.18 & -0.43 & -0.48 & - & & \\
4. Certainty & 5.34 & 1.58 & 0.19 & 0.19 & $0.04^{*}$ & - & \\
5. Objective know. & 6.94 & 1.38 & $-0.03 *$ & $0.07 *$ & $0.00^{*}$ & 0.13 & - \\
\hline
\end{tabular}

Note.

*: non-significant. 


\section{Table 3.}

Testing hypotheses by hierarchical moderated regression model

\begin{tabular}{|c|c|c|c|c|c|c|c|c|}
\hline \multirow{2}{*}{\multicolumn{3}{|c|}{$\begin{array}{l}\text { Variables/Hypothese } \\
\text { s/Results } \\
\text { (Supported) }\end{array}$}} & \multicolumn{2}{|c|}{ Basic Model } & \multicolumn{2}{|c|}{ Moderation Model } & \multicolumn{2}{|c|}{ Extended Model } \\
\hline & & & \multirow{2}{*}{$\begin{array}{r}\text { Std. } \beta \\
0.63\end{array}$} & \multirow{2}{*}{$\frac{\text { t-values }}{12.6 * * *}$} & \multirow{2}{*}{$\begin{array}{r}\text { Std. } \beta \\
0.55\end{array}$} & \multirow{2}{*}{$\frac{\mathrm{t} \text {-values }}{11.3 * * *}$} & \multirow{2}{*}{$\begin{array}{r}\text { Std. } \beta \\
0.45\end{array}$} & \multirow[t]{2}{*}{ t-values } \\
\hline $\mathrm{S}$ & $\mathrm{H} 1$ & Sup. & & & & & & \\
\hline $\mathrm{S} \times \mathrm{R}$ & $\mathrm{H} 2$ & Sup. & & & -0.16 & $-2.5^{*}$ & -0.17 & $-2.5 *$ \\
\hline $\mathrm{S} \times \mathrm{OK}$ & H3 & Sup. & & & 0.14 & $2.3 *$ & 0.14 & $2.3 *$ \\
\hline $\mathrm{S} \times \mathrm{C}$ & $\mathrm{H} 4$ & Sup. & & & 0.17 & $2.8 * *$ & 0.19 & $3.0 * *$ \\
\hline $\mathrm{R}$ & & & & & & & -0.32 & $-5.0 * * *$ \\
\hline $\mathrm{OK}$ & & & & & & & 0.07 & $1.4^{\mathrm{ns}}$ \\
\hline $\mathrm{C}$ & & & & & & & 0.14 & $2.8 * *$ \\
\hline \multicolumn{3}{|c|}{$\mathrm{R}^{2}$ loyalty $(\%)$} & \multicolumn{2}{|c|}{39.3} & \multicolumn{2}{|c|}{44.1} & \multicolumn{2}{|c|}{49.7} \\
\hline \multicolumn{3}{|c|}{$\Delta \mathrm{R}^{2}$ loyalty $(\%)$} & \multicolumn{2}{|c|}{-} & \multicolumn{2}{|c|}{4.8} & \multicolumn{2}{|c|}{5.6} \\
\hline \multicolumn{3}{|c|}{ Effect size (ES) } & \multicolumn{2}{|c|}{-} & \multicolumn{2}{|c|}{0.12} & \multicolumn{2}{|c|}{0.13} \\
\hline \multicolumn{3}{|c|}{ Chi-square (df), Sig. } & \multicolumn{2}{|c|}{$17.2(8), p=0.028$} & \multicolumn{2}{|c|}{$29.1(23), p=0.155$} & \multicolumn{2}{|c|}{204.8 (109), $\mathrm{p}=$} \\
\hline \multicolumn{3}{|l|}{ GFI } & \multicolumn{2}{|c|}{0.99} & \multicolumn{2}{|c|}{0.98} & \multicolumn{2}{|c|}{0.94} \\
\hline \multicolumn{3}{|l|}{ CFI } & \multicolumn{2}{|c|}{0.10} & \multicolumn{2}{|c|}{0.10} & \multicolumn{2}{|c|}{0.98} \\
\hline \multicolumn{3}{|c|}{ RMSEA } & \multicolumn{2}{|c|}{0.06} & \multicolumn{2}{|c|}{0.03} & & \\
\hline
\end{tabular}

Notes.

$* p<0.05 ; * * p<0.01 ; * * * p<0.001 ;$ ns: nonsignificant

$E S=\left(R_{Y, M i+1}^{2}-R_{Y, M i}^{2}\right) /\left(1-R_{Y, M i+1}^{2}\right) ; Y=$ Loyalty and $i=1,2,3($ Mi $=$ Model $i)$.

L: Loyalty; S: Satisfaction; R: Perceived risk; OK: Objective knowledge; C: Certainty. 


\section{APPENDIX - PAPER 4:}

SCALE AND ITEMS

\begin{tabular}{llc}
\hline Scale & \multicolumn{1}{c}{ Items } & Cronbach's \\
\hline Health risk & I would say that choosing to eat marine fish (1) is & 0.79 \\
& risky for health; (2) unsafe; (3) If I were to tell a friend \\
& about marine fish, I would describe marine fish as \\
& risky food for health \\
Performance & When I buy marine fish: (1) I am concerned that it \\
risk & will not be as I expected; (2) I am concerned that it \\
& will not meet my requirements; (3) I am never sure I \\
& have chosen the right product \\
Psychological & In many cases: (1) I feel stress when deciding to buy \\
risk & marine fish for my family meals; (2) I feel my family \\
& members dislike the marine fish I buy; (3) I feel my \\
& great \\
& family members refuse to eat the marine fish I buy \\
& (1) I feel that the ability to face financial risk when \\
buying fish is high; (2) Given the expenses involved & 0.85 \\
&
\end{tabular}




\section{DESCRIPTIVE STATISTICS}

\begin{tabular}{lccccc}
\hline Constructs and indicators & Mean & $\begin{array}{c}\text { Std. } \\
\text { Dev. }\end{array}$ & $\begin{array}{c}\text { Skew- } \\
\text { ness }\end{array}$ & Kurtosis & N \\
\hline Satisfaction & & & & & \\
Unpleasant/Pleasant & 4.16 & 1.81 & -0.24 & -0.94 & 387 \\
Unsatisfied/Satisfied & 4.16 & 1.75 & -0.27 & -0.80 & 387 \\
Not liking/Liking & 4.11 & 1.78 & -0.23 & -0.86 & 387 \\
Loyalty & & & & & \\
Past frequency & 2.88 & 1.32 & 0.55 & -0.01 & 387 \\
Recent frequency & 2.77 & 1.38 & 0.44 & -0.77 & 387 \\
Behavioral expectation & 3.08 & 1.52 & 1.68 & 4.04 & 387 \\
Certainty & & & & & \\
Certainty - Unpleasant/Pleasant & 5.34 & 1.69 & -0.80 & -0.37 & 387 \\
Certainty - Unsatisfied/Satisfied & 5.35 & 1.64 & -0.78 & -0.20 & 387 \\
Certainty - Not liking/Liking & 5.35 & 1.65 & -0.86 & -0.08 & 387 \\
Perceived risk & & & & & \\
Health & 3.45 & 1.42 & 0.35 & -0.01 & 387 \\
Performance & 4.68 & 1.52 & -0.32 & -0.53 & 385 \\
Social & 3.81 & 1.47 & 0.11 & -0.25 & 386 \\
Financial & 3.27 & 1.52 & 0.25 & -0.38 & 387 \\
Objective knowledge & & & & & \\
Objective knowledge score & 6.94 & 1.38 & -0.58 & -0.06 & 387 \\
\hline
\end{tabular}

